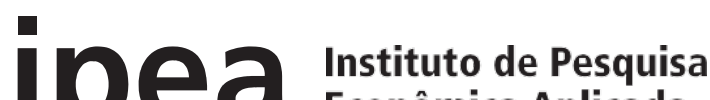 Econômica Aplicada
}

\begin{tabular}{|c|c|}
\hline Título do capítulo & $\begin{array}{l}\text { CAPÍTULO } 11 \\
\text { GOVERNANÇA METROPOLITANA E DEMOCRACIA NA } \\
\text { AMÉRICA LATINA: ALGUMAS SUGESTÕES PARA A } \\
\text { AMPLIAÇÃO DA AGENDA DE PESQUISA }\end{array}$ \\
\hline Autor(es) & Klaus Frey \\
\hline DOI & DOl: http://dx.doi.org/10.38116/978-65-5635-017-2cap11 \\
\hline Título do livro & $\begin{array}{l}\text { Governança Metropolitana na América Latina: um panorama } \\
\text { das experiências contemporâneas sob uma mirada } \\
\text { comparativa }\end{array}$ \\
\hline Organizadores(as) & $\begin{array}{l}\text { Marco Aurélio Costa } \\
\text { Lizandro Lui } \\
\text { Sara Tavares Rebello }\end{array}$ \\
\hline Volume & 4 \\
\hline Série & Governança Metropolitana na América Latina \\
\hline Cidade & Rio de Janeiro \\
\hline Editora & Instituto de Pesquisa Econômica Aplicada (Ipea) \\
\hline Ano & 2021 \\
\hline Edição & $1 a$ \\
\hline ISBN & $978-65-5635-017-2$ \\
\hline DOI & DOl: http://dx.doi.org/10.38116/978-65-5635-017-2 \\
\hline
\end{tabular}

(C) Instituto de Pesquisa Econômica Aplicada - ipea-2020

As publicações do Ipea estão disponíveis para download gratuito nos formatos PDF (todas)

e EPUB (livros e periódicos). Acesse: http://www.ipea.gov.br/portal/publicacoes

As opiniões emitidas nesta publicação são de exclusiva e inteira responsabilidade dos autores, não exprimindo, necessariamente, o ponto de vista do Instituto de Pesquisa Econômica Aplicada ou do Ministério da Economia.

É permitida a reprodução deste texto e dos dados nele contidos, desde que citada a fonte. Reproduções para fins comerciais são proibidas. 


\section{GOVERNANÇA METROPOLITANA E DEMOCRACIA NA AMÉRICA LATINA: ALGUMAS SUGESTÕES PARA A AMPLIAÇÃO DA AGENDA DE PESQUISA'}

Klaus Frey²

\section{INTRODUÇÃO}

Este artigo visa contribuir com o tema da governança metropolitana na América Latina, com base no estudo comparativo realizado pelo grupo de pesquisadores latino-americanos no âmbito do Programa Executivo de Cooperação em Políticas Públicas para o Desenvolvimento Econômico, Social e Ambiental do Brasil e da América Latina, por meio de reflexóes sobre algumas questôes que o estudo suscita em relaçáo aos avanços e limites da ampliação de espaços democráticos de governança, articulaçáo e cooperação em nível metropolitano. Não pretendo fazer uma análise comparativa dos diferentes estudos, já realizada de forma muito elucidativa por Cid Blanco, no capítulo 9 deste volume, mas sim apontar possibilidades para uma futura ampliação da agenda de pesquisa, com ênfase na dimensão democrática da governança regional ou metropolitana em vista da atual conjuntura e de conflitos emergentes que em meu entender tornam necessário repensar alguns conceitos tradicionais relativos à governança metropolitana.

Parto, portanto, da avaliação preliminar de que, no caso brasileiro pelo menos, o "vazio político e administrativo" (Souza, 2003, p. 149) em nível metropolitano deixado pela Constituição de 1988 (CF/1988) tem sido ao menos parcialmente preenchido pelo legislador nacional sobretudo por meio do Estatuto da Metrópole - embora, conforme nos lembre Blanco no seu capítulo, pouco dos instrumentos propostos foi de fato incorporado na prática do planejamento e da governança das regióes metropolitanas (RMs) do país. De modo similar, de acordo com as avaliaçóes dos autores do relatório, apesar dos diversos avanços observados em termos institucionais em todos os países considerados, porém diferenciados quanto à abrangência e profundidade dos arranjos institucionais encontrados, a governança metropolitana na América Latina, de forma geral,

1. DOI: http://dx.doi.org/10.38116/978-65-5635-017-2cap11

2. Professor titular em políticas públicas na Universidade Federal do $A B C$ (UFABC); integra o projeto Planejamento e Governança do Desenvolvimento Sustentável de Regiões Metropolitanas no Brasil e na América Latina no contexto das mudanças climáticas. E-mail: <klaus.frey@ufabc.edu.br>. 
ainda continua frágil, com grandes dificuldades de lidar adequadamente, ou seja, de forma coordenada e cooperativa, com aqueles problemas que necessitam de respostas regionalmente integradas.

Além disso, parto de avaliaçóes realizadas anteriormente (Frey, 2012; 2019) sobre como a habitual predominância da lógica tecnocrática do planejamento tem contribuído para uma despolitização das escalas regionais e metropolitanas como espaços de articulação e confrontação democrática e, consequentemente, para a relutância, por parte dos principais atores políticos - locais e estaduais, sobretudo -, de assumir e valorizar essa escala como arena democrática válida. Essa relutância pode se revelar trágica em vista dos desafios que as grandes metrópoles vêm crescentemente enfrentando, requerendo uma alta capacidade de cooperaçáo e de resoluçáo de conflitos em tempos de crescentes incertezas.

Este artigo se divide em quatro seçóes. Além desta introdução, abordaremos o atual contexto no qual a governança metropolitana tem que se consolidar, sobretudo a crise da democracia liberal e alguns cruciais desafios que se colocam à governança das grandes metrópoles em tempos de crescentes riscos e incertezas. $\mathrm{Na}$ seção seguinte, seguem algumas consideraçóes sobre a pesquisa cujos resultados são apresentados neste livro, identificando algumas preocupaçóes complementares a partir das experiências empíricas relatadas que apontam para novas indagaçóes em possíveis estudos futuros. Concluímos com algumas reflexóes e sugestóes referentes à ampliação da agenda de pesquisa sobre governança metropolitana na América Latina em perspectiva comparativa.

\section{ATUAL CONTEXTO: CRISE DEMOCRÁTICA E NOVOS DESAFIOS À GOVERNANÇA METROPOLITANA}

Quando falamos sobre a governança das RMs, é óbvio que a forma como se organiza o Estado é de central importância em uma Federação ou um Estado unitário, uma vez que essa decisão e suas regulações específicas definem as responsabilidades e competências entre os entes governamentais. Isso se torna fundamental para se pensar e organizar a necessária cooperação intergovernamental nas RMs. Quando falamos da influência do regime político, no entanto, temos que olhar para além da forma de Estado - unitário ou federativo -, considerando o sistema democrático como um todo; isto é, todo um ambiente político-institucional que vai além dos arranjos institucionais específicos, mas que envolve os sistemas eleitoral, de partidos políticos, da mídia, o chamado quarto poder, as relaçóes Estado-sociedade, entre outros aspectos que condicionam, constrangem ou impulsionam a dinâmica política e, com isso, também as possibilidades da governança metropolitana.

Nas últimas décadas, processos de democratização e descentralização ocorreram em quase todos os países estudados, acompanhados de um processo 
de relativo enfraquecimento do Estado nacional, por sua vez apoiado pelas agências internacionais de desenvolvimento. Como parte de uma estratégia de neoliberalização, receitou-se a descentralização como elemento crucial das políticas de ajuste estrutural, visando ao fortalecimento dos mercados, à boa governança e ao fortalecimento democrático, particularmente em nível local (Cheema e Rondinelli, 2007; Frey, 2008). Essa agenda neoliberal, todavia, resultou em uma capacidade estatal fragilizada, uma infraestrutura pública precária, um nível de serviços públicos insuficiente para proteger a população de riscos e ameaças, como vivenciamos atualmente com tanto sofrimento devido à pandemia da Covid-19, como também na tendência de redução dos laços de solidariedade social e intergovernamental (Frey, 2020).

$\mathrm{O}$ vácuo de governança em nível metropolitano na nova república se explica, portanto, de um lado, pela descentralização e pelo fortalecimento do poder local como "reação à metrópole, como resistência ao centralismo do poder" (Davidovich, 2015, p. 203) do regime militar, promovendo uma "retórica municipalista exacerbada" (Azevedo e Guia, 2015, p. 106); e, de outro, pelo movimento do neoliberalismo, com sua valorizaçáo do princípio da competitividade, inclusive entre jurisdições públicas e municipais, em detrimento da cooperação e do compartilhamento de responsabilidades (Abrucio, 2005).

Ao identificar o poder local com o processo de democratização e a gestão metropolitana com os regimes militares e a centralização do poder, os avanços das práticas de democracia participativa nos países da América Latina têm se limitado basicamente ao nível municipal. Na maior parte dos países latino-americanos da época da chamada "onda rosa" (Lambert, 2010) -, nomeada assim devido ao fato de governos de esquerda e centro-esquerda terem sido eleitos nesses países a partir do final da década de 1990 -, observou-se um fortalecimento da sociedade civil e uma abertura de canais participativos, de "espaços convidados" (Miraftab, 2018) e chancelados pelos governos, que recorreram a essas instituiçóes participativas nas suas estratégias políticas com o objetivo de promover transformação social com justiça social. Com poucas exceçôes, como na política ambiental, nada semelhante ocorreu em nível regional.

Os receios relacionados a um fortalecimento da escala metropolitana estão, portanto, tradicionalmente relacionados à possibilidade de um enfraquecimento do poder local - espaço privilegiado de mobilização e organização social e política - e, com isso, da própria democracia. Tendo em vista que os avanços em termos de democratização, ampliação da participação popular e fortalecimento da sociedade civil concentram-se basicamente em âmbito municipal, não parecem sem fundamento os temores acerca dos potenciais riscos relacionados à 
recentralização e tecnocratização acompanhando o fortalecimento institucional em nível metropolitano.

Os riscos de maior concentração de poder se tornam ainda mais agudos em função da atual crise da democracia liberal (Castells, 2018), acompanhada da ascensão do populismo, do autoritarismo e de uma extrema polarização da opinião pública que torna acordos entre governos cada vez mais difíceis. No Brasil, o recente embate e a falta de articulação e diálogo entre o governo nacional e os governos subnacionais em torno do enfrentamento da pandemia da Covid-193 (Frey, 2020) têm evidenciado um processo de mudança de um modelo de governança interfederativa baseada no protagonismo da União, que recorre à negociação e a mecanismos de indução financeira como principais mecanismos de coordenação das políticas públicas (Arretche, 2012), em direção a

uma outra forma de funcionamento da Federação que combina a defesa de maior autonomia dos governos subnacionais com a redução da responsabilidade do governo federal no campo das políticas públicas, mas que, num aparente paradoxo, pretende instituir isso desconsiderando os estados e municípios, a fim de enfraquecer a participação destes entes federativos na deliberação e controle das decisôes tomadas em Brasília (Abrucio et al., 2020).

Assim sendo, temos que constatar que a cooperação e a solidariedade, princípios essenciais para o bom funcionamento de uma Federação, de um federalismo cooperativo, vêm se deteriorando aceleradamente na medida em que o governo nacional não cumpre sua função de coordenação e de mediação nas relaçóes intergovernamentais e, ao contrário, ainda instiga a polarização e o conflito interfederativo. Como demonstram Levitsky e Ziblatt (2018, p. 20), o desrespeito contínuo às normas democráticas não escritas da tolerância, da contenção dos governantes, isto é, do comedimento no uso de prerrogativas institucionais, abre o caminho para a sepultura da democracia.

Esse vácuo de governança interfederativa em nível nacional tende a aumentar, de forma geral, a desconfiança nas relaçóes intergovernamentais, a não ser que surjam resistências e novas alianças entre governos subnacionais capazes de contrabalançar, pelo menos parcialmente, essa alta conflitualidade nas relaçóes interfederativas. Nesse contexto político conflitivo, novos desafios vêm afetando os países e as nossas metrópoles, como as epidemias ou mudanças climáticas que, por sua própria natureza, desrespeitam qualquer tipo de delimitação jurisdicional e, portanto, só podem ser enfrentados de forma efetiva na base da cooperação interjurisdicional e intergovernamental. Isso vale tanto para as dimensóes globais e planetárias de tais fenômenos quanto para suas dimensóes transnacionais, regionais ou intermunicipais. Resulta disso a necessidade de olharmos para além 
das estruturas institucionais habitualmente propostas nas legislaçóes formais e de averiguarmos o potencial explicativo e a relevância empírica de novas concepçóes teóricas relativas à governança pública que nos apoiam na identificação de arranjos e práticas de governança ajustados aos problemas característicos da atual conjuntura.

Temos os já conhecidos problemas e transformaçóes das metrópoles latino-americanas relacionados à expansão dos territórios urbanizados, às fragilidades da infraestrutura urbana, sobretudo nas áreas periféricas e de riscos, ao aumento da poluição, das desigualdades sociais, territoriais e econômicas no contexto de um capitalismo global extremamente interconectado e interdependente - pelo menos até a deflagração da pandemia da Covid-19 -, que fizeram com que, a partir dos anos 1990, a governança das RMs e das cidades-regiōes retornasse com bastante força à agenda política. Esses esforços de promover as metrópoles e cidades-regióes - como é o caso também da macrometrópole paulista - foram antes de mais nada economicamente motivados (Davoudi, 2008, p. 58; Frey, 2019, p. 2). Contudo, os novos riscos e incertezas relacionados à deterioração das condiçóes socioambientais e às mudanças climáticas ou ainda às endemias dificilmente têm se constituído fatores relevantes na determinação de arranjos institucionais de governança regional. Entendemos, pois, que seja fundamental a abertura das estruturas de governança ao envolvimento da ciência e da sociedade civil, com seus conhecimentos plurais e suas preocupaçóes pertinentes, para tornar os processos de deliberação política mais bem fundamentados, mais democráticos e reflexivos.

\section{ESTUDO COMPARATIVO SOBRE GOVERNANÇA METROPOLITANA NA AMÉRICA LATINA}

A pesquisa sobre a governança metropolitana na América Latina apresentada nesta coletânea é de extrema importância pois indica, de forma sistematizada: i) os marcos legais dos oito países - Argentina, Brasil, Chile, Colômbia, Equador, México, Peru e Venezuela - e suas implicaçóes para os processos de formação das RMs; ii) suas principais estruturas institucionais; iii) as ênfases específicas quanto aos serviços prestados em nível metropolitano; iv) e os instrumentos de planejamento e financiamento. Dessa forma, temos um panorama geral sobre a situação da governança metropolitana em cada país. Além disso, com os estudos de caso realizados, as pesquisas nos proporcionam também relevantes informações sobre os avanços e dificuldades na implementação dos marcos legais em algumas metrópoles selecionadas.

Embora Cid Blanco, no capítulo comparativo do estudo, chegue a uma avaliação de que os oito casos "possuem mais semelhanças do que diferenças no tema metropolitano", é oportuno olhar para as particularidades institucionais e 
políticas e, com isso, para as margens de ação que os países possuem, sobretudo os atores políticos e diferentes regióes, na questão da democracia, preocupação maior deste artigo.

$\mathrm{Na}$ ciência política tem destaque a abordagem teórica da chamada path dependence, ou dependência de trajetória, empregada para explicar mudanças institucionais, sobretudo o fato de essas mudanças ocorrerem com frequência apenas gradualmente, em função dos custos transacionais envolvidos em quaisquer mudanças de trajetória. Essa perspectiva tem indicado que apenas em momentos críticos, como em crises ou eventos impactantes, janelas de oportunidades são abertas para rupturas ou ao menos para mudanças mais significativas de trajetória. Souza (2003) recorre a esse referencial teórico para explicar, no caso brasileiro, por que as RMs não sobreviveram, ou só de forma parcial, ao processo constituinte, considerado por ela um "momento crítico" na trajetória da governança metropolitana no processo de redemocratizaçáo.

Não é minha intenção questionar a importância das experiências autoritárias e a histórica preponderância do poder federal nas políticas públicas desde os anos 1930 para os processos decisórios em torno da CF/1988. Cabe frisar, todavia, que a teoria da dependência de trajetória permite sempre interpretar certos acontecimentos como consequência de um momento crítico de mudança em função de seu caráter de excepcionalidade - isto é, como reação a uma situação prévia que tem se tornado insustentável, apesar de todos os custos de transação em jogo - ou como uma evidência das forças das instituiçôes que não permitiram uma verdadeira mudança de trajetória por conta justamente desses custos de transação. No final, na retrospectiva, é sempre mais fácil adaptar o argumento da teoria aos fatos consumados.

Isso não quer dizer que a teoria ou sua interpretação do caso concreto esteja equivocada, mas sim que essa abordagem nos permite visualizar que a história poderia ter se desenrolado de forma diferente. Na época da redemocratização, se os movimentos urbanos, os urbanistas e inclusive o movimento municipalista tivessem tido maior consciência da gravidade da situação nas grandes metrópoles e/ou das chances que uma abordagem cooperativa poderia acarretar para os governos municipais, e se tivesse havido lideranças com alta capacidade de convencimento, as negociações no processo constituinte poderiam ter resultado na proposição de um modelo democrático de governança metropolitana capaz de garantir uma influência mais significativa dos governos municipais e da sociedade civil nas questôes metropolitanas, ocasionando sua aceitação e legitimidade democrática.

Há de se considerar que essa suposição é apenas hipotética. Contudo, ela é necessária para ressaltar que a força explicativa da teoria da dependência de trajetória parece bem maior para explicar a morosidade das mudanças institucionais 
em condiçóes de relativa estabilidade política do que as rupturas políticas e institucionais em momentos críticos da história. É por isso que a ciência política e o institucionalismo tendem a apresentar dificuldades na interpretação, mais ainda na previsão, de transformaçôes político-institucionais de maior amplitude. Nesses momentos críticos, o desenrolar das coisas depende sobremaneira das estratégias dos atores e das dinâmicas políticas e sociais, mas também de fenômenos externos como crises econômicas ou ambientais, cujo conhecimento torna-se crucial para compreender e interpretar adequadamente mudanças ou rupturas institucionais em curso ou para classificá-las posteriormente.

Por essa razão, proponho, ao analisar os capítulos deste volume, além de averiguar a tendência geral dos países, dar também atenção às peculiaridades que nos fazem ter uma ideia sobre o papel dos atores e de sua "capacidade de agência" (Machado-da-Silva, Fonseca e Crubellate, 2005) nos processos de transformação e, consequentemente, sobre as condicionantes que favorecem mudanças mais substanciais, não obstante os custos de transação envolvidos em tais decisóes. Temos de entender o processo de mudança institucional como uma interação contínua entre estruturas institucionais e agência, entre ordem e mudança, deixando margem de manobra para a "criatividade política, pela qual pessoas em ambientes plurais experimentam e praticam regras e papéis" (Berk, Galvan e Hattam, 2013, p. 2).

Por isso, como afirma Blanco no capítulo 9 deste livro, embora devamos reconhecer a importância dos "processos de urbanização e de metropolização ocorridos na regiáo" como condicionantes estruturais da governança metropolitana, constrangendo de forma semelhante as possibilidades de ação dos governos da região, esse ambiente estrutural náo impede os governantes de serem criativos na busca de soluçóes alternativas e democráticas, fugindo da tendência geral da centralização do poder e do planejamento tecnocrático.

Os estudos desta pesquisa levantaram diversas iniciativas que indicam possibilidades de democratizaçáo e de participação popular na governança metropolitana. Nos casos de Venezuela, Colômbia e Equador houve envolvimento dos municípios e da população na própria formação de RMs por meio de iniciativa popular ou ratificação por consulta popular. No caso dos países que possuem instâncias deliberativas, verificou-se que apenas na Colômbia e no Brasil está prevista uma representação da sociedade civil com direito a voto, enquanto em instâncias consultivas, via de regra, a participação da sociedade civil é assegurada, apresentando, no entanto, variaçóes quanto ao peso da sociedade civil nesses fóruns. Permanecem, todavia, dúvidas sobre a efetividade dessas participaçôes em termos das relaçóes de poder, como no caso colombiano, em que apenas uma organização sem fins lucrativos está prevista para defender as posiçóes da sociedade civil em 
uma instância dominada pelos atores governamentais. Se esses diversos arranjos de fato conseguem garantir, segundo Blanco, "transparência e participação na tomada de decisóes" é algo para ser verificado por pesquisas qualitativas.

Como Blanco afirma ainda, os estudos de caso apontaram que existe também um desconhecimento dos cidadãos sobre as instâncias participativas metropolitanas e até mesmo da existência da própria governança metropolitana. É interessante notar que embora o caso considerado neste estudo como best case (da governança metropolitana do Valle de Aburrá, na Colômbia, tendo a cidade de Medellín como principal protagonista) conte com parceiros da sociedade civil ligados ao mercado, no âmbito da Agência de Cooperação e Investimento de Medellín e Área Metropolitana (ACI, 2011), ao mesmo tempo dispensa a participação da sociedade civil nos seus processos de tomada de decisão na Área Metropolitana del Valle de Aburrá (AMVA). É algo que merece nossa reflexão. Parece que a própria literatura vem privilegiando e valorizando aquelas experiências de estruturas institucionais intergovernamentais robustas, promovidas pelos governos, enquanto a participação popular recebe uma atenção apenas secundária, sendo considerada um elemento a mais que deveria ser agregado ao regime de governança assim que for consolidado.

No nosso entender, no entanto, é de crucial importância dar mais atenção ao papel das organizaçóes da sociedade civil na governança regional e metropolitana. Como nos lembra Oakerson (2004, p. 20), "a governança é o trabalho de pessoas de dentro e de fora de governos". Não é suficiente ter vontade governamental e estabelecer estruturas institucionais supostamente capazes de encontrar soluçôes para os problemas regionais das grandes metrópoles. Diversas experiências mais exitosas (Frey, 2012) demonstram que, na prática da governança metropolitana, outros aspectos precisam ser levados em consideração, como a função de liderança desempenhada por atores-chave, a existência e promoção de uma identidade regional, além da força organizativa e política da sociedade civil em nível regional.

Esses três fatores, de acordo com a literatura, tiveram influência decisiva em experiências destacadas no debate brasileiro. É o caso do Consórcio Intermunicipal do Grande $A B C$ na RM de Sáo Paulo, em que a liderança do prefeito e do governador da época, o papel ativo desempenhado pela sociedade civil e a existência prévia de uma identidade regional compartilhada pela população da regiáo foram apontados como os principais fatores de sucesso da experiência. Além disso, houve a implementação de um consórcio, que abrangeu também uma câmara e uma agência de desenvolvimento, e, na sua fase inicial, um fórum da cidadania, com amplo envolvimento e protagonismo da sociedade civil (Frey, 2012; Klink, 2008). 
Outro exemplo de experiência exitosa é a RM de Belo Horizonte, onde foi estipulado, nos anos 2000 , por parte do governo estadual, um arranjo institucional complexo para as duas RMs de Minas Gerais,

composto por uma Assembleia Metropolitana, um conselho de desenvolvimento com reduzida - mas importante - participaçáo da sociedade civil, uma agência para implementação de políticas, planos e projetos, um fundo de desenvolvimento metropolitano, e um plano diretor de desenvolvimento para a regiāo metropolitana (Costa, Oliveira e Almeida, 2018, p. 300).

No caso específico da RM de Belo Horizonte foi criado ainda um conselho deliberativo com dois representantes eleitos em conferências metropolitanas da sociedade civil. Em uma dessas conferências foi instituído o Colegiado Metropolitano, formado por vinte representantes da sociedade civil como fórum paralelo, informal, um "espaço de ação inventado" na concepção de Miraftab (2018), a partir do qual são escolhidos pela própria sociedade os seus representantes, atuando com maior legitimidade democrática e força de convencimento no conselho deliberativo.

Outra experiência que faz da RM de Belo Horizonte um caso de referência é a cooperação existente entre poder público, universidades e a sociedade na elaboração do Plano Diretor de Desenvolvimento Integrado da RM de Belo Horizonte e de planos diretores municipais, cujo princípio da sustentabilidade do desenvolvimento serviu como orientação geral para o processo cooperativo de planejamento (Costa, Oliveira e Almeida, 2018).

Vale lembrar também os comitês de bacias hidrográficas, nos quais governos, sociedade civil e setor empresarial colaboram na gestão e no planejamento, sendo um "espaço de articulação, de negociação, de debate de problemas [que] abre espaço para a expressão e defesa dos interesses difusos” (Jacobi, 2005, p. 83).

Esses diferentes casos demonstram a significativa variedade de arranjos de governança nas RMs, inclusive arranjos informais, que existem e são resultado dessa criatividade política desempenhada tanto por governos quanto pela sociedade civil e que faz a diferença, mesmo em contextos estruturais desfavoráveis. Percebe-se também que não existe uma panaceia institucional para a governança metropolitana, mas sim a necessidade de se pensar em arranjos institucionais mais flexíveis e adaptados aos desafios variados que esses territórios vêm enfrentando, demandando novas perspectivas teóricas para sua apreensão e interpretação. 


\section{CONTRIBUIÇÕES PARA A AMPLIAÇÃO DA AGENDA DE PESQUISA COMPARATIVA SOBRE GOVERNANÇA METROPOLITANA NA AMÉRICA LATINA}

Em tempos de aquecimento global e de Covid-19, os países e as metrópoles são confrontados com desafios gigantescos. No início de maio de 2020, Nova York, epítome da metrópole moderna, lamentou a morte de aproximadamente $18 \mathrm{mil}$ pessoas e uma sobrecarga extrema do sistema de saúde por causa da pandemia da Covid-19. Ao mesmo tempo, observou-se que a situação das metrópoles da América Latina estava evoluindo na mesma direção, com algumas exceções, como Santiago do Chile, com até agora apenas sete mortes relatadas. ${ }^{4}$

O aumento de eventos climáticos extremos por causa do aquecimento global é outra ameaça que deve atormentar as RMs com intensidade crescente, sobretudo os territórios mais densamente povoados. A pressão por mudanças importantes, muitos diriam radicais, aumenta a cada emergência que castiga as metrópoles.

Em geral, os governos, quando sob pressão, em situaçóes de crise, reagem com centralização e concentração do poder. Mesmo em casos em que há estruturas participativas, o papel desses arranjos se fragiliza. Por exemplo, no caso da crise hídrica que acometeu a RM de São Paulo em 2014-2015, houve uma forte centralização do poder em nível do governo estadual, com a imposição de "um modelo de gestão baseado na engenharia", simplesmente ignorando as propostas alternativas apresentadas pela sociedade civil (Santos et al., 2018, p. 287). O mesmo padrão autoritário e tecnocrático é observado na atual crise da Covid-19, em que a falta de diálogo efetivo entre governo, sociedade e ciência contribui para a limitada disposiçáo de partes da sociedade em seguir as regras impostas unilateralmente pelos governos (Frey, 2020).

Com todos esses problemas, implicando possíveis efeitos extremamente severos para a populaçáo das metrópoles e envolvendo riscos, incertezas e muitas vezes escolhas trágicas para os tomadores de decisão, os nossos regimes políticos mais ou menos democráticos - chegaram a uma bifurcação de extrema gravidade: ou fortalecer a democracia, o papel da sociedade e as práticas deliberativas dialogadas, reflexivas e cooperativas, ou se render gradualmente às tendências autoritárias e tecnocráticas que as condiçóes de emergências e de crises acarretam se não houver esforços explícitos de oposição e resistência. Está em jogo o futuro da democracia e de nossas liberdades, ou seja, será o fim da democracia liberal tal como a conhecemos até hoje, com todas as suas limitaçóes, pois, como Bobbio (1986, p. 21) nos adverte, "Estado liberal e Estado democrático, quando caem, caem juntos". 
Vem dessa preocupação com o futuro de nossa democracia, atualmente sob ataque por movimentos populistas de uma direita em ascensão na América Latina e no mundo (Mounk, 2019) - chegando, no Brasil, ao cúmulo de seu presidente, eleito democraticamente, encabeçar manifestaçôes antidemocráticas em plena pandemia da Covid-19 -, a necessidade de reforçar a atenção pela salvaguarda e, consequentemente, pelo aprofundamento da democracia, sobretudo nas grandes metrópoles, onde essa luta entre democracia e autoritarismo vem sendo travada de forma cada vez mais intensa.

Chama atenção que, no passado, havia bem menos estudos sobre governança metropolitana e regional enfocando as questóes da democracia e da sustentabilidade. A ênfase recaía, em geral, sobre as preocupaçôes relacionadas à performance das instituiçóes metropolitanas e à competitividade regional (Tomàs, 2020 , p. 34). Com base nas experiências europeias, Zimmermann e Getimis (2017, p. 208) afirmam que "acadêmicos e profissionais têm dado prioridade a assuntos como empreendedorismo, competição e performance de instituições metropolitanas, ao passo que negligenciaram assuntos de redistribuição, democracia local, justiça social e desafios ambientais".

Essa afirmação se aplica da mesma maneira à América Latina. Na pesquisa apresentada nesta coletânea, com sua ênfase nos marcos legais, a democracia é um assunto entre muitos, e os resultados revelam, por um lado, em graus variados, mecanismos institucionais que a princípio permitem participação e accountability; e, por outro lado, sugerem, via de regra, a pouca efetividade desses arranjos no dia a dia da governança metropolitana nos estudos de caso. Em compensaçáa, observa-se que diversos estudos de caso indicam que inovaçóes promovidas por governos ou pela própria sociedade civil acarretam um promissor potencial de democratização da governança metropolitana orientada pela sustentabilidade. Ou seja, não só as instituições contam - também os atores, os protagonistas da sociedade civil e, de forma geral, lideranças com uma visão mais ampla fazem diferença para a governança.

Face ao exposto, gostaríamos de fazer, a seguir, alguns apontamentos finais para uma eventual ampliação da agenda de pesquisa sobre governança metropolitana e democracia na América Latina em perspectiva comparada.

- Expansão da agenda para pesquisas qualitativas sobre boas práticas a partir do levantamento panorâmico das dimensóes estruturais da governança metropolitana na América Latina na base dos marcos legais, é fundamental um avanço para pesquisas qualitativas e sistematizadas para assim permitir comparabilidade dos resultados. Já existem hoje importantes estudos de caso isolados, mas que náo seguem um desenho único de pesquisa e não enfocam variáveis comuns na base 
de abordagens teóricas compartilhadas. Estudando inovaçóes políticas criativas de governança metropolitana, com base em um referencial teórico-metodológico comum, proporcionaria importantes perspectivas sobre as condicionantes estruturais e as capacidades de agência para uma governança metropolitana democrática e eficiente.

- Ênfase em temas de alta relevância para o futuro das metrópoles - como evidenciamos neste capítulo, as estratégias metropolitanas na América Latina ainda parecem mirar quase exclusivamente os problemas tradicionais da urbanizaçáo e do desenvolvimento econômico no contexto da globalização, enquanto os desafios do futuro precisam estar mais relacionados a situaçóes de risco, de emergências e das injustiças daí decorrentes, como no caso da Covid-19; e à sustentabilidade, sobretudo as mudanças climáticas, o que deve exigir um repensar da democracia, de nossos modos de desenvolvimento e de nossas abordagens teóricas de governança.

- Ampliação das perspectivas teóricas - existe hoje uma literatura bastante significativa sobre governança que crescentemente leva em consideração a necessidade de as práticas de governança precisarem se adequar às novas incertezas, aos riscos e às complexidades que os novos desafios aqui citados nos apresentam. Influências emergem das discussôes sobre a sustentabilidade, a gestâo de recursos naturais e a própria democracia. Enquanto uma boa parte da literatura - e da legislação - sobre governança metropolitana ainda parte, na base do paradigma funcional, da concepção de uma solução institucional única, senão para todas as RMs, pelo menos para todas as áreas de atuação de cada uma delas, diversos estudos demonstram a necessidade de promover uma maior pluralidade de arranjos institucionais, formais e informais, consequentemente considerando diferentes abordagens teóricas. Sugiro, portanto, explorar, em estudos comparativos futuros sobre governança metropolitana, abordagens inovadoras como governança interativa, participativa, deliberativa, policêntrica, multinível, adaptativa, resiliente ou antecipatória quanto ao seu potencial de sustentar pesquisas comparativas na América Latina, aumentando assim a compreensão sobre as potencialidades da governança metropolitana em uma democracia em acelerada transformação.

Quanto às políticas climáticas locais e regionais, visando à sustentabilidade, mitigação e adaptação às mudanças climáticas, temos globalmente um crescente número de relatos de boas experiências, como os esboçados em Dawson (2018), Barber (2017) ou Beck (2018), que nos proporcionam algum motivo para esperar 
que as necessárias mudanças poderiam emergir das cidades. Mesmo em relação ao combate à Covid-19, há casos de municípios ou de grupos de municípios que avançam com iniciativas inovadoras. Exemplo disso é o Consórcio do Grande $\mathrm{ABC}$, na RM de Sáo Paulo: além de criar um site informativo sobre a evolução da epidemia em toda a regiáo, ${ }^{5}$ coopera com uma iniciativa da UFABC no desenvolvimento de uma ferramenta on-line para identificar casos suspeitos de coronavírus, visando aumentar o entendimento da transmissão comunitária ${ }^{6}$ e desenvolvendo várias outras iniciativas importantes com o envolvimento de todos os sete municípios da região (Passarelli, 2020). São experiências que remetem à importância da criatividade política e da cooperaçáo como recurso essencial na reinvenção da governança em tempos de aquecimento global e pandemia.

Esperamos que essa proposta de ampliação da agenda de pesquisa sobre governança metropolitana na América Latina possa contribuir com algumas ideias para a continuidade do programa de pesquisa mantido pelo Ipea e pela Comissão Econômica para a América Latina e o Caribe (Cepal) e o avanço no aprimoramento da governança metropolitana latino-americano em acordo com os variados desafios que nos esperam nos tempos vindouros, relacionados à sustentabilidade e salvaguarda da democracia.

\section{REFERÊNCIAS}

ABRUCIO, F. L. A coordenação federativa no Brasil: a experiência do período FHC e os desafios do governo Lula. Revista de Sociologia e Política, n. 24, p. 41-67, 2005.

ABRUCIO, F. L. et al. Mais Brasil, Menos Brasília: o sentido do federalismo bolsonarista e seu impacto no combate à Covid-19. Estadáo, 12 abr. 2020. Disponível em: <https://politica.estadao.com.br/blogs/gestao-politica-e-sociedade/ mais-brasil-menos-brasilia-o-sentido-do-federalismo-bolsonarista-e-seu-impactono-combate-a-covid-19/>. Acesso em: 13 abr. 2020.

ACI - AGENCIA DE COOPERACIÓN E INVERSIÓN DE MEDELLÍN Y EL ÁREA METROPOLITANA. Medellín, la región y el mundo: una mirada de la Agencia de Cooperación e Inversión de Medellín y el Área Metropolitana ACI (algunos conceptos y lineamientos básicos para afrontar el reto de la internacionalización desde lo local). Medellín: ACI, 2011. p. 1-13.

ARRETCHE, M. Democracia, federalismo e centralizaçáo no Brasil. Rio de Janeiro: Editora FGV; Editora Fiocruz, 2012.

5. Disponível em: <https://coronavirus.consorciograndeabc.page/>.

6. Disponível em: <https://covidata.ufabc.edu.br/>. 
AZEVEDO, S. de; GUIA, V. R. dos M. Os dilemas institucionais da gestão metropolitana no Brasil. In: RIBEIRO, L. C. de Q. (Org.). Metrópoles: entre a coesão e a fragmentação, a cooperação e o conflito. 2. ed. Rio de Janeiro: Letra Capital, 2015. p. 97-110.

BARBER, B. R. Cool cities: urban sovereignty and the fix for global warming. New Haven: Yale University Press, 2017.

BECK, U. A metamorfose do mundo: novos conceitos para uma nova realidade. Rio de Janeiro: J. Zahar, 2018.

BERK, G.; GALVAN, D. C.; HATTAM, V. Beyond dualist social science: the mangle of order and change. In: . (Ed.). Political creativity: reconfiguring institutional order and change. Philadelphia: University of Pennsylvania Press, 2013. p. 1-26.

BOBBIO, N. O futuro da democracia: uma defesa das regras do jogo. Rio de Janeiro: Paz e Terra, 1986.

CASTELLS, M. Ruptura: a crise da democracia liberal. Rio de Janeiro: Zahar, 2018.

CHEEMA, G. S.; RONDINELLI, D. A. From government decentralization to decentralized governance. In: (Ed.). Decentralizing governance: emerging concepts and practices. Washington: Brookings, 2007. p. 1-20.

COSTA, H. S. de M.; OlIVEIRA, A. M.; ALMEIDA, D. A. O. de. Buscando um urbano metropolitano a partir da natureza e da cultura: uma discussão a partir do caso da região metropolitana de Belo Horizonte. In: CARNEIRO, J. M. B.; FREY, K. (Org.). Governança multinível e desenvolvimento regional sustentável: experiências do Brasil e da Alemanha. São Paulo: Oficina Municipal, 2018. p. 297-320.

DAVIDOVICH, F. A "volta da metrópole" no Brasil: referências para a gestão territorial. In: RIBEIRO, L. C. de Q. (Org.). Metrópoles: entre a coesão e a fragmentação, a cooperação e o conflito. 2. ed. Rio de Janeiro: Letra Capital, 2015. p. 197-230.

DAVOUDI, S. Conceptions of the city-region: a critical review. Urban Design and Planning, v. 161, n. 2, p. 51-60, 2008. Disponível em: <https://www. icevirtuallibrary.com/doi/abs/10.1680/udap.2008.161.2.51>.

DAWSON, A. Extreme cities: the peril and promise of urban life in the age of climate change. London; New York: Verso, 2018.

FREY, K. Development, good governance, and local democracy. Brazilian Political Science Review, v. 2, n. 2, p. 39-73, 2008. 
Abordagens de governança em áreas metropolitanas da América Latina: avanços e entraves. Revista Brasileira de Gestáo urbana, v. 4, n. 1, p. 87-102, 2012. - Global city-region. In: ORUM, A. M. (Ed.). The Wiley Blackwell encyclopedia of urban and regional studies. New Jersey: John Wiley \& Sons, 2019.

- Democracia, ciência e políticas públicas no contexto da Covid-19. Dossiê Covid-19, n. 5, p. 33-34, 2020. Disponível em: <http://pesquisa.ufabc. edu.br/macroamb/dialogos-socioambientais-na-macrometropole-paulista-no-5covid19/>. Acesso em: 5 maio 2020.

JACOBI, P. R. Comitês de bacias hidrográficas: o que está em jogo na gestão compartilhada e participativa. In: DOWBOR, L.; TAGNIN, R. A. (Ed.). Administrando a água como se fosse importante. São Paulo: Editora Senac, 2005. p. 81-88.

KLINK, J. Governos e governança metropolitana: o caso do ABC paulista. In: DOWBOR, L.; POCHMANN, M. (Org.). Políticas para o desenvolvimento local. São Paulo: Editora FPA, 2008. p. 275-291.

LAMBERT, R. A onda rosa. Le Monde Diplomatique, 1 abr. 2010. Disponível em: <https://diplomatique.org.br/a-onda-rosa/>.

LEVITSKY, S.; ZIBLATT, D. Como as democracias morrem. Rio de Janeiro: J. Zahar, 2018.

MACHADO-DA-SILVA, C. L.; FONSECA, V. S. da; CRUBELLATE, J. M. Estrutura, agência e interpretação: elementos para uma abordagem recursiva do processo de institucionalização. Revista de Administração Contemporânea, v. 9, p. 9-39, 2005.

MIRAFTAB, F. Insurgent practices and decolonization of futures. In: GUNDER, M.; MADANIPOUR, A.; WATSON, V. (Ed.). The Routledge handbook of planning theory. New York: Routledge, 2018. p. 276-288.

MOUNK, Y. O povo contra a democracia: por que nossa liberdade corre perigo e como salvá-la. São Paulo: Companhia das Letras, 2019.

OAKERSON, R. J. The study of metropolitan governance. In: FEIOCK, R. C. (Ed.). Metropolitan governance: conflict, competition, and cooperation. Washington: Georgetown University Press, 2004. p. 17-45.

PASSARELLI, S. O enfrentamento da Covid-19 no ABC Paulista. Dossiê Covid-19, n. 5, p. 15-16, 2020. Disponível em: <http://pesquisa.ufabc.edu. $\mathrm{br} / \mathrm{macroamb} /$ dialogos-socioambientais-na-macrometropole-paulista-no-5covid19/>. Acesso em: 5 maio 2020. 
SANTOS, I. P. de O. et al. Water transfers and institutional standstill: coalitions set in the access-to-water conflict in São Paulo. In: POUPEAU, F. et al. (Ed.). Water conflicts and hydrocracy in the Americas: coalitions, networks, policies. São Paulo: Editora USP, 2018. p. 271-291.

SOUZA, C. Regióes metropolitanas: condicionantes do regime político. Lua Nova, n. 59, p. 137-158, 2003.

TOMÀS, M. Metropolitan revolution or metropolitan evolution? The (dis) continuities in metropolitan institutional reforms. In: ZIMMERMANN, K.; GALLAND, D.; HARRISON, J. (Ed.). Metropolitan regions, planning and governance. Cham: Springer, 2020. p. 25-39.

ZIMMERMANN, K.; GETIMIS, P. Rescaling of metropolitan governance and spatial planning in Europe: an introduction to the special issue. Raumforschung und Raumordnung: Spatial Research and Planning, v. 75, n. 3, p. 203-209, 2017. 